\title{
Gaining by Giving? Peer research into service user and carer perceptions of inclusivity in Higher Education
}

\author{
Joy M Rooney \\ Institute of Health and Society \\ University of Worcester, Worcester, WR2 6AJ, UK \\ j.rooney@worc.ac.uk \\ Peter F Unwin \\ Institute of Health and Society \\ University of Worcester, Worcester, WR2 6AJ, UK

\section{Nina Osborne} \\ Institute of Health and Society \\ University of Worcester, Worcester, WR2 6AJ, UK
}

Service users and carers (SUAC) have made significant contributions to professional training in social work courses in Higher Education (HE) over the past decade in the UK. Such participation has been championed by government, academics and SUAC groups from a range of theoretical and political perspectives. Most research into the effectiveness of SUAC involvement at HE has come from the perspectives of academics and very little SUAC-led research exists. This qualitative peer research was led by two members of the University of Worcester's SUAC group.

Findings were that SUAC perceived their involvement brought benefits to students, staff, the University and the local community. Significant personal benefits such as finding a new support network, increased self-development and greater confidence to manage their own care were identified in ways that suggested that the benefits that can flow from SUAC involvement at HE are perhaps more far-reaching than previously recognised. Barriers to inclusion were less than previously reported in the literature and the humanising effects of SUAC involvement are presented as a partial antidote to an increasingly marketised HE culture.

Keywords: service user and carer; social work; peer research; inclusivity; higher education; widening participation; lifelong learning

\section{Introduction}

For more than a decade the University of Worcester, England, has included service users and carers (SUAC) in the recruitment and education of its students, in its quality processes and in 
its research endeavours. In England, the use of SUAC in academic settings is encouraged by both legislation and policy, particularly given recent concern about standards in practice (e.g. Francis, 2013). SUAC involvement in qualifying social work training has been mandatory since 2002 (Department of Health, 2002) and SUAC involvement within policy was first identified in The National Health Service and Community Care Act (1990) wherein a model of consumerism was promoted in an emerging patient- led NHS. Part of New Labour's marketisation and modernisation agenda for the NHS was designed to enable more choice for SUAC with a focus on including them in the delivery and service design of their own care (Department of Health, 2006). Similar policies of modernisation and marketisation have also come to dominate HE in England (Jary, 2014). This consumerist agenda can be critiqued as an anti-professional neo-liberal stance which views health and social care services as businesses in which the customer is king (Harris, 2003). Glasby \& Beresford (2006) promote SUAC involvement, specifically in the research arena, as a necessary antidote to the elitist hierarchy that has characterised western academic research. Such a view positions SUAC knowledge as a different kind of knowledge, rather than an inferior type of knowledge, to that held by senior academics and professionals.

This paper reports the results of research led by the University of Worcester's SUAC group, 'IMPACT', into perceptions regarding the SUAC role both within the university and in regard to the wider community. SUAC perceptions regarding any associated achievements, benefits, or barriers to inclusion were also explored. The IMPACT group has been involved in teaching and learning, recruitment and selection, quality assurance and research since 2008 and had 21 members at the time of the research project. Apart from one BME group member, all other participants are White British. The IMPACT group is made up of a variety of people who use services relating to physical disability (n.6), mental health services (n.2), substance abuse (n.2), domestic violence (n.1) chronic illness (n.1) or are carers (n.8) or care leavers (n.1). The research team comprised of two IMPACT members and an academic, the IMPACT members taking the lead in all aspects of fieldwork, analysis and write-up with the academic member being involved in the research analysis and write-up.

\section{Literature Review}

SUAC involvement might be usefully analysed via Arnstein's (1969) Ladder of Citizen Participation:

(INSERT HERE) Figure 1. Eight Rungs on a Ladder of Citizen Participation (Arnstein, 1969)

This seminal model portrays a hierarchical construct of participation, placing 'Manipulation' on the bottom rung, along with 'Therapy', which are together classified as representing forms of non-participation in that they are seen are dishonest and patronising. The next rungs on the ladder - 'Informing', 'Consultation' and Placation' are grouped together as 'Tokenism' in that a decision has probably already been made by the organisation in question and citizens are being given information rather than choice, being asked questions about a decision already made or being falsely reassured that there is nothing to worry about. The top three rungs on the ladder - 'Partnership', 'Delegated Authority' and 'Citizen Control' are grouped together as 'Citizen Power' - and are seen to apply when decisions and planning matters are joint affairs, when citizens genuinely have at least some delegated authority to make a decision. Citizen Control indicates a form of participation whereby citizens design, plan and carry executive responsibility for an organisation or part of an organisation. Arnstein's model was developed from the field of urban planning but can be adapted to the situation of SUAC involvement in HE. 
There is some reported SUAC - led research (e.g. Barber et al., 2011; Brett et al., 2014; Faulkner, 2010; Gillard \& Stacey, 2005; Gillard, et al 2012; Hutchinson \& Lovell, 2013; Patterson et al., 2014; Wallcraft et al., 2012), which particularly relates to the health oriented Patient and Public Involvement (PPI) literature. With regard to the effect of SUAC involvement in research, Brett et al. (2014) systematically reviewed 66 studies of PPI involvement and demonstrated that, despite a relatively weak evidence base (due partly to the nature of SUAC involvement not always being made clear), health and social work research has benefitted from PPI in the enhancement of the quality of research and in having better assured its appropriateness and relevance. This was particularly found to be the case when SUAC involvement was toward the top rungs of Arnstein's (1969) ladder, namely when SUAC were involved from design through to analysis and dissemination, rather than in sporadic or tokenistic ways.

McKeown et al. (2012) included three SUAC researchers in focus group research into why people elected to participate in the University of Central Lancashire SUAC group 'Comensus'. Their key findings suggested that SUAC participants used 'activist' concepts in making sense of their social relations. SUAC wished for social change, not personal gain, became more self-aware and felt valued, worked in a democratic way and benefitted from comradeship and sociability with other Comensus members. SUAC participants also became involved in a wider set of issues than their initial initiative and also wrote and led their own modules on the practice of involvement (McKeown et al., 2012).

In respect of SUAC involvement in health and social work in the UK, there has been little systematic progress made in evidencing its nature and its outcomes (McCutcheon \& Gormley, 2014; Wallcraft et al., 2012). Despite some government initiatives (e.g. Department of Health, 2002) to further develop initiatives between SUAC, academics and practice, Rhodes (2012), concluded a literature review by stating that much more research is necessary to determine the effect of service users in transformative learning and care delivery. Towle et al. (2010) reviewed active patient involvement in the education of health professionals internationally and found a wide range of activity but no evidence suggesting any change in the behaviour of learners as a result of exposure to SUAC as part of their education.

\section{Barriers to SUAC Participation in Health and Social Care Education}

Barriers are widely reported to still exist regarding the meaningful inclusion of SUAC in professional education across health and social care (Bassett et al., 2006; Lathlean et al., 2006 \& Speed et al., 2012). Basset et al. (2006: 395 - 400) identified 10 barriers to SU participation in mental health education and training. These were:

- hierarchies that exclude

- stigma and discrimination —not a service user-friendly atmosphere

- validation and accreditation processes

- academic jargon and 'put-downs'

- clever people/clever excuses

- knowledge as king and topics/levels

- individual and not team approach

- gaining access in the first place

- bureaucratic payment systems

- lack of support for trainers/educators. 
Lathlean et al. (2006: 425) cited four barriers to SUAC involvement in healthcare education:

- the perception of service user involvement as being threatening to staff and their sense of professional autonomy

- the stress of involvement may damage users' health

- service users themselves may be reluctant or lack interest with factors such as age, gender, cultural background, diagnosis, previous health care experiences personality characteristics and educational background playing a part

- $\quad$ service users are not adequately remunerated for their contributions.

Speed et al. (2012), from a sample of 38 SUAC groups across the North West of England, determined the potential barriers to SUAC involvement in nurse education as:

- not knowing the context of the group

- lack of preparation of the group

- not being supported, not being allowed to be real

- not receiving feedback

- not being paid appropriately.

As suggested by these above barriers the involvement of SUAC in HE is not straightforward, rather it is a complex undertaking full of issues around power / hierarchies / rights / language / stigma / remuneration and logistics. The methodology outlined below of using SUAC researchers to seek SUAC views in this project was designed to minimise some of these hierarchical / language and power barriers in the belief that fuller and franker data might result.

\section{Methodology}

The present research project came about as the result of an IMPACT sub-group which promotes and carries out research. Members suggested that a focus on the motivations for involvement seemed to be an area lacking in research which could possibly be used to add to knowledge as well as inform future recruitment/retention strategies. After an initial group discussion, two IMPACT members volunteered to take the lead in research design and implementation, working in partnership with the academic facilitator of IMPACT on subsequent analysis, write-up and dissemination of findings.

The method chosen by the two IMPACT researchers was one of conducting semi-structured interviews by Skype telephoning, a method previously used by the researchers and one which could produce rich data, as well as offering IMPACT members choice over when the interviews took place. Recordings were subsequently anonymised and transcribed. Core questions, designed by SUAC researchers, revolved around exploring whether there were any perceived benefits or disadvantages to students, the Institute of Health and Society, the University and the wider community from SUAC involvement. Questions were concerned with whether any personal achievements and benefits were perceived as flowing from their involvement within the fields of teaching and learning/ recruitment, quality assurance and research. Additionally, a question was asked about any perceived barriers to fuller 
involvement with IMPACT and whether there were any views about whether IMPACT involvement brought any benefits to other community groups of which the participant might also be a member.

Ethical approval was granted by the Ethics Committee of the Institute of Society and Health at the University of Worcester. Invitations to participate and the associated consent forms were sent by e-mail to individuals on the data base of the IMPACT group (n. 21). The two SUAC researchers, also members of IMPACT, were not included in the research sample. Each IMPACT member who expressed interest in the research was then telephoned and invited to return their consent form if they wished to participate. Fifteen semi-structured interviews with eleven female and four male respondents were subsequently carried out by Skype telephoning, this response level constituting 79\% of the IMPACT membership eligible for interview. Reasons for those that did not participate included ill health or ill health in those they cared for, and lack of available time.

Recordings of the interviews were subsequently anonymised and transcribed. Both SUAC researchers independently analysed the interviews using thematic analysis and then met with their academic colleague to discuss and agree their findings.

\section{Key Findings}

The research found that SUAC perceived that their involvement in HE brought benefits to students, to the Institute of Health and Society, to the University and to the wider community. Additionally, there was significant evidence of contributions made and personal achievements and benefits received by being members of IMPACT. Barriers preventing greater involvement were identified and suggestions for improving SUAC involvement were also made. The six key themes that emerged were those of:

1. Perceived direct benefits to the students in the Institute of Health and Society through SUAC involvement in learning, selection and teaching

\section{Perceived corporate benefits to the University}

3. Perceived benefits of 'the two way street' whereby group members brought experience and insight to the University and took new knowledge and insights back to their organisations

4. Perceived value of contributions made to students and staff across the Institute of Health and Society that may translate into practice

5. Perceived achievements and benefits to SUAC

6. Perceived barriers to SUAC involvement including accessibility, organisational and personal barriers.

These themes are presented in detail below:

1. Perceived Direct Benefits to the Students in the Institute of Health and Society through SUAC involvement in Learning, Selection and Teaching 
The direct benefits of SUAC activities were mentioned 20 times by 15 respondents and fell into the following three categories - student learning, the teaching of students and student / staff selection:

With regard to student learning, students' confidence was perceived as having been built up through direct contact with the SUAC experience (4), either by direct testimony received or by SUAC having interacted with the same students over the duration of a course. Students were perceived as having been enabled to learn what impacts on people's lives across a wide range of diverse groups and situations (3) and the quality of student readiness for practice was seen as having improved. SUAC respondents also believed that they provided a safe learning and research resource for students (2).

With regard to teaching, students were perceived as having benefitted from exposure to the reality of SUAC emotion in the 'safety' of the classroom (2); theory was related more to practice in the SUAC teaching sessions (1); a rounder, more holistic learning experience for students was offered (1) and there was opportunity to question SUAC within a classroom environment (1) without fear of sanction.

With regard to student selection, there were perceived impacts on the quality of student recommended for admission across social work and related courses (2) and a different perspective to the selection processes was provided, emphasising assessment of soft skills and value base (3) from the SUAC perspective.

Commentary - The above findings suggest that SUAC believe that they bring distinctive and valued aspects to student learning, teaching and student selection, perspectives that have not been detailed in the literature.

\section{Perceived Corporate Benefits to the University}

The corporate benefits of IMPACT as an organisation were recognised in 19 instances by 15 respondents and comments encompassed the following themes:

- IMPACT brings a humanist perspective to a world of academia that is increasingly pre-occupied with targets and league tables (8)

- IMPACT was perceived as a 'hub' for the dissemination SUAC involvement across the University (2)

- Helping to meet course requirements for accreditation (4)

- Enhanced reputation for inclusion (2)

- Ticks boxes and gets 'brownie points' (2)

- Increases opportunities to access funding for courses/research (1).

Commentary - It is interesting to note respondents' views that staff also benefit from being reminded of the human side to their teaching and learning activities, which can all too easily be marginalised in a performance-managed culture. Respondents clearly demonstrated their awareness of the University's need to be able to demonstrate sufficient levels of SUAC engagement to gain accreditation and to pass audits / inspections but these comments were interpreted as being realistic rather than cynical and there was no suggestion that involvement was perceived as either mercenary or tokenistic. 
3. Perceived benefits of 'the two way street' whereby group members brought experience and insight to the University and took new knowledge and insights back to their organisations

Respondents mentioned that they carried out paid work in social care settings (2). Other respondents mentioned organisations or community initiatives with which they were involved (8). These were mainly voluntary organisations plus one member was a SUAC representative on The College of Social Work (TCSW) Board (The English Coalition Government had established TCSW in 2012 to champion and promote best practice across social work, including the involvement of SUAC. The College was in place at the time of this research but was unexpectedly shut down by government in 2015, some of its functions transferring to the British Association of Social Workers (BASW), others to the private sector and others being lost).

From the above responses it can be seen that the type and level of contributions to the widening community are very varied but in all cases members felt that IMPACT both provided benefits to, and benefitted from, their various other involvement and employment roles. Responses included:

I take increased awareness and ideas about how to do service user and carer involvement into my job role

...two-way general benefit through self-broadening

I'm more open to different ways of working

....work experience enhances IMPACT role play, learning from diverse membership of IMPACT can be applied in work situations

....definitely a two-way flow- able to suggest speakers, think of different ways of working, more thoughtful about the kind of services needed and understanding of how things could be streamlined.

Commentary - The above responses demonstrate a two-way flow of learning and awareness facilitated by IMPACT members which helps the University to both deliver courses more effectively and to discharge its expressed strategies of inclusivity and widening participation. The sharing of insights, information and skills with those organisations with which IMPACT members are also involved was mentioned by a majority of respondents as an important spinoff from participation.

4. Perceived Value of Contributions made to Students and Staff across the Institute of Health and Society

Specific areas of experience that SUAC respondents believed they offered included:

- Helping staff learn / gain breadth of understanding about SUAC issues, leading to them valuing SUAC colleagues more (2)

- Presenting a strong and credible SUAC voice that offered real time, contemporary information on issues such as the effects of social policy and legislation (2)

- Modelling advocacy in acting as a proxy for SU lacking capacity (1) and speaking as a member of ethnic minority (1) 
- Improvement of course materials and policies though listening to the views and experiences of SUAC and acting on these perspectives in activities such as involving SUAC in the design and audit of curriculum (4).

Commentary - Respondents valued the richness of their diverse backgrounds and experiences and seemed very aware of how important this grass-roots perspective was for both staff and students.

\section{Perceived Achievements and Benefits to SUAC}

Fourteen respondents identified having made positive personal achievements, between them giving 38 examples of what they felt they achieve:

Sense of achievement/purpose (19)

The greatest response was that of feeling valued (5), followed by making a difference/ contributing (3), the knowledge that they were helping / useful (2) and finding the experience itself rewarding (2) were also significant positives mentioned by respondents. Other notions were those of self-satisfaction, still working to benefit others, using skills and professional expertise, promoting disabled people as equals, seeing people you have helped to select go on to become professionals, being recognised by students for their contributions, finding students' regard for SUAC involvement a 'breath of fresh air' and being given a new lease of life:

With my involvement with IMPACT, I felt treated very much like an equal and somebody with something to offer, and so that's been very positive

Well I feel that I've come in with a fresh approach to how I perceive how I would like to be treated as a patient

You are valued as a carer... and there are things for you to do which are meaningful, that does give me a really good sense of value.

\section{Access to training/ learning (9)}

A diverse set of issues were recognised in this area regarding the broadening of understanding/ increasing one's own knowledge (2). Some other areas mentioned were keeping up to date in health and social care, being encouraged to take further training, being enabled to rekindle research skills and having access to University facilities / learning,

Enjoyment/ increased emotional wellbeing (11)

Responses in this area included regained confidence (3), interesting/enjoyable work (2), helped me come out of myself, personal development, treated with respect/ as equal, sense of belonging, changed attitude about work opportunities and finding the IMPACT work enjoyable/ having a good laugh - "Oh gosh, yes. It's amazing, yeah. It's actually given me a lot more confidence, definitely. It's helped me to come out of myself a little bit more”.

People also felt that being a member of IMPACT gave them a voice, made them better at building relationships and helped them develop a more positive outlook on their personal situation: 
Yeah, so personal development, because I have sort of developed as a person, and the way I speak and I'm more focused on trying to get the outcomes to when I first started. So it's obviously been appealing to me as well as to the students and the academics that I've worked with.

\section{Social networking / group support (6)}

In this group, 20 separate references were made to the emotional and supportive benefits of involvement including the opportunity to work with interesting / varied people (3), social networking/group support (2), and help in overcoming risks of isolation / de-skilling.

Fifteen responses cited practical benefits stemming from involvement which included being part of a community, knowing what is going on at the University and having contact with others about lived experience. Other responses included being paid (2) and one person had achieved a job beyond the university which they partly attributed to confidence gained by way of IMPACT activities. People also appreciated being able to update or gain new knowledge, learning reflective and resilience techniques, doing something properly in a supported setting and being able to work for the local good in terms of influencing the next generation of health and social care professionals. An overarching benefit of doing something stimulating is highlighted in the following quotes:

It stops the brain cells, I suppose, from vegetating completely in retirement. Because it is stimulating and makes me think. I'm interested. It gives me another tack to think about and to explore

Actually being a part of the University, I never would have thought I'd be working alongside the University. That's absolutely amazing. So yeah, I absolutely love it.

Commentary - This section is emphatic in its acknowledgement of the achievements and benefits perceived by individuals through participation in IMPACT. The identification of new social support networks, peoples' increased levels of self-awareness, confidence and emotional resilience suggest that there are overall long term benefits to participation for SUAC.

\section{Perceived Barriers to SUAC Involvement including Accessibility, Organisational and Personal Barriers}

The four themes that emerged in this area were those of Accessibility, Organisational barriers, Personal barriers and Time constraints

Accessibility Barriers were perceived by respondents (12) as comprising:

- Inappropriate/repetitive work times such as early starts or late finishes that are challenging for those needing or arranging care (2).

This matter has been raised by the IMPACT facilitator with colleagues and is being addressed by working with staff to increase awareness about appropriate timings, roomings and the need for appropriate breaks in long sessions. 
- Expectation that members are competent with technology.

Training is offered to IMPACT members in the use of technology and alternative communication methods are also being used which respect individual SUAC circumstances and abilities.

- Poor communication regarding meeting details.

A set format for communications and a 'catch all' plan has been developed for last minute instructions. Dedicated administrative support for IMPACT has been successfully lobbied for by IMPACT members and the IMPACT facilitator.

- Excessive distances to travel (3).

It has been accepted that it is not reasonable to ask IMPACT members to travel significant distances for short sessions. Where possible, extra activities are planned that are designed to account for at least a half day input.

- Mileage being "mean" at 25p a mile (2).

Travel is paid for all IMPACT activities but this rate set is a corporate rate which it has not, as yet, proved possible to change.

- Formatting of e-documents for screen reader/individual needs.

The particular needs of IMPACT members are being addressed incrementally by the University's IT specialists, many of these needs being similar to those of students with impairments.

- Arrangements and costs of support workers and scribes.

A strategy has been developed for organising such support, making use of services previously only made available to students. All additional support worker costs incurred by partaking in IMPACT activities are paid from the IMPACT budget, which has been increased accordingly. A system has been brought into play with the help of the new administrative support that better guarantees equality of opportunity and participation of all IMPACT members in all activities.

- University perceived as an elite establishment "not for people like me":

Community facilities are now offered as an option for initial meetings with potential IMPACT members to lessen any stigma that might be attached to University premises for people who have never been to a University.

Organisational barriers (10), major were seen as:

- Not enough members/diversity within membership.

Prior to this study, recruitment to IMPACT had largely been by word of mouth. This strategy tended to attract similar members to the existing members, the vast majority of whom were White British, Wider recruitment drives are now in place, supported by an information pack and a user-friendly application form, designed by IMPACT members. Members from a wider range of ethnic backgrounds have been recruited as a result of this new approach.

- Lack of awareness of what is happening in IMPACT.

A communication strategy has been developed which includes periodic updates on all work streams. The work streams of Recruitment and Selection / Quality Assurance / Learning and Teaching and Research meet three times per year, now supplemented by a twice yearly meeting of the whole group. An online newsletter is also in the process of development.

- Limited utilisation of some members / Systems for work allocation not clear / Short notice of work allocation.

A clear strategy is now in place that avoids any perceptions of favouritism in respect of letting IMPACT members know about work opportunities. This appears to be working well. Staff have been asked to give reasonable timeframes when requesting IMPACT involvement 
although some requests for IMPACT involvement inevitably come with short notice requirements.

- Rate of remuneration not having increased.

The rate of pay has now been increased by $£ 2-50$ p.h. to $£ 12.50$ p.h. The rate for teaching / leading seminars has remained static at $£ 18.00$ in line with wider University policy regarding visiting lecturer rates.

Personal barriers (10)

- Personal health/stamina (5).

Flexibility is built into work delivery plans and it is accepted that some SUAC will need to 'step back' from time to time. A co-operative culture has developed within the group and members will sometimes ask each other to substitute in regard to a commitment they are unable to fulfil due to personal circumstances.

- $\quad$ Lack of care cover/child care (2).

While IMPACT cannot facilitate the actual child care, any additional costs incurred by way of IMPACT duties are now covered by its budget.

- Lack of skills or knowledge (2).

Training sessions regarding activities such as Research and Recruitment / Selection are run on an annual or bi-annual basis and a system of individual appraisal is being developed to better ensure that all IMPACT members work to their potential.

- Need for a regular income.

Engagement of IMPACT members is dependent on demand, which fluctuates from semester to semester, hence it is not possible to assure a regular level of income from IMPACT duties.

Time constraints (10)

- $\quad$ Busy lifestyle / family life (5), Work / study commitments (2) and Carer responsibilities (3).

It is inevitable that the everyday caring and coping demands on SUAC will limit their availability for IMPACT. Such pressures are accommodated within IMPACT's systems, including payments to cover caring responsibilities. Clear communication to enable advanced planning is taking place with improved awareness of replacement carer/ childcare payments.

Commentary - Although the above comments indicate the presence of real and ongoing barriers for respondents continuing their involvement with IMPACT, these are being addressed within IMPACT and the University as discussed above. The presentation of such candid comments might be seen as partly due to the research having been led by peer researchers. The wider resonance of these issues with previous research in this area will be further discussed below.

\section{Discussion}

This current study, led by two SUAC researchers, has produced some noteworthy findings, particularly around the themes regarding perceived achievements and benefits to SUAC participants in HE. These add to those achievements and benefits of wider SUAC 
participation reported elsewhere (e.g. Barber et al., 2011; Brett et al., 2014; Faulkner, 2010; Gillard \& Stacey, 2005; Gillard et al. 2012; Hutchinson \& Lovell, 2013; Patterson et al., 2014; Wallcraft et al., 2012). Other findings of this study, such as those that perceive considerable benefits to the education of students, corroborate other non-SUAC led research findings about such benefits (e.g. Anghel \& Ramon, 2009; Chambers \& Hickey, 2012).

Brett et al. (2014) found that research benefitted from SUAC involvement when that involvement was systemic from conceptualisation through to dissemination. The present study can be viewed as according with this model and also valuable in respect of its clarity regarding the actual parts played by SUAC in the overall research, Brett et al. (2014) having criticised much previous literature due to its lack of specificity about the SUAC role. Involvement in IMPACT can be seen to be largely perceived by SUAC respondents as fitting with Arnstein's (1969) 'Partners' rung, which is within the sub- grouping of 'Citizen Control', although the two higher rungs in this sub-category - 'Delegated Power' and 'Citizen Control' do not seem to be reflected in the findings. Indeed, in respect of coproduction as applied to SUAC involvement in HE, more delegated power and citizen control might not equate as being 'top of the ladder'. For example, in social work student recruitment and in the assessment of role plays and biographical, reflective pieces, SUAC already have delegated authority but any marking is always negotiated with an academic partner. This joint knowledge is seen as the best knowledge and there were no respondents asking for more power and control in this research, rather they wished for closer and more transparent partnerships.

Beresford \& Glasby's (2010) view that SUAC knowledge should be seen as of equal value to academic knowledge appeared to be reflected in SUAC perceptions of the value they bring to staff and students in HE. The perception that this knowledge, combined with personal growth and development, is also carried back to benefit their own organisations is a new research finding, warranting further enquiry. Positive partnership working between staff and SUAC is demonstrated in this study, as is the lack of stigma and discrimination associated with SUAC involvement that has been widely reported in previous publications (Basset et al., 2006; Lathlean et al., 2006; Speed et al., 2012). Basset et al. (2006) listed ten types of barriers to participation and only two, namely the gaining of access in the first place and SUAC groups at HE perhaps operating on an individual rather than a team basis, can be seen to feature in the present study's findings. Lathlean et al. (2016) identified barriers to SUAC involvement to comprise staff seeing such involvement as threatening, SUAC finding involvement damaging to their health, SUAC being reluctant to engage and remuneration being inadequate. There was some evidence of reluctance to engage found in the present study, largely to do with feelings that universities were not for "people like me" although steps have since been taken to allay such stigma with potential new recruits, such as offering first meetings outside of university premises. The issue of inadequate remuneration did feature in the present study and steps have again been taken since the study to remedy some of these concerns, although others, such as mileage rates, have remained unchanged. Speed et al. (2012), with specific reference to nurse education, had found that SUAC were often unprepared and unsupported by staff in regard to the context of their involvement, that no feedback was received and that remuneration was again inadequate. These issues, apart from that of remuneration, were absent from the present study.

Nevertheless, the research project also acted as a 'Health Check' for IMPACT after eight years of operation and, despite its many positive findings, the perceived barriers to participation were of particular concern, leading to some of the changes in practice discussed above. It is perhaps encouraging that these barriers were largely perceived by SUAC 
respondents as barriers that could be overcome in a spirit of partnership, suggesting that some of Glasby \& Beresford's (2006) aspirations for a lessening in hierarchical practices within HE are actually happening. The responses regarding barriers were candid and might have been so as a result of SUAC peers having conducted the field research. As suggested by Barber et al. (2011), peer researchers might be viewed as theoretically more likely to bring out candid responses in fieldwork. While this study cannot claim generalisability, the extent and depth of disclosure as well as the level of constructive criticism about changes needed in IMPACT, can be hypothesised to have been less likely to have flowed from a more hierarchical form of research, such as that led by academics.

\section{Conclusions}

The overall achievements and benefits perceived by SUAC participants in this study are considerable. SUAC respondents reported being given a sense of purpose, access to training / learning, personal development / increased emotional wellbeing, practical and material benefits, social networking and peer support. Such findings are similar, although more farranging, to those reported by Towle \& Godolphin (2015).

The rich and candid findings that have emerged from this peer-led research study are distinctive in their depiction of SUAC themselves benefiting significantly from their own involvement in HE. 'Gaining by Giving' is the overarching and novel theme which stands out from the key findings, a theme which represents an important role for universities in the ever-marketised world of HE. The SUAC members of the IMPACT group perceive that they benefit greatly in terms of personal development and wellbeing while the University of Worcester receive the input of the widening community to give added value across a wide range of functions. This added value was perceived as relating to the selection of students, teaching, learning, staff knowledge and awareness, curriculum development, feedback, research and corporate compliance with national policies and requirements. However, in line with the findings of Towle et al. (2010) and Rhodes et al. (2014), no hard evidence emerged in this study regarding SUAC involvement having brought about transformative change in the learning or practice behaviour of students, which is the main aim of SUAC involvement within HE. Further research, co-produced between academics and SUAC, into the effects on subsequent practice in social work and associated fields is needed to ascertain whether SUAC learning is translated into practice.

Universities in England operate on business models whereby league tables and performance indicators can make them lose sight of one of their core purposes, namely being part of, and educating, a community. Widening participation and including non-traditional members is an aim often to be found in the corporate-speak of universities' prospectuses and strategic plans. The University of Worcester's IMPACT Group has convinced its own members that inclusivity and widening participation are realities rather than aspirations. This is not to forget also that the educational experiences of staff and students were perceived as being wellserved via their exposure to the diverse and varied experiences of IMPACT members, experiences that will hopefully be translated into practice.

\section{References}

Anghel, R., \& Ramon, S. (2009). Service users and carers' involvement in social work education: lessons from an English case study. European Journal of Social Work, 12, 185-199. doi: 10.1080/13691450802567416 
Arnstein, S. (1969). A Ladder of Citizen Participation. Journal of the American Planning Association, 35, 216-224. doi: 10.1080/01944366908977225

Barber, R., Beresford, P., Boote, J., Cooper, C., \& Faulkner, A. (2011). Evaluating the impact of service user involvement on research: a prospective case study. International Journal of Consumer Studies, 35, 609-615. doi: 10.1111/j.1470-6431.2011.01017.x

Basset, T., Campbell, P., \& Anderson, J. (2006). Service User/ Survivor Involvement in Mental Health Training and Education: Overcoming the Barriers. Social Work Education, 25, 393-402. doi: 10.1080/02615470600593675

Beresford, P. (2007). User involvement, research and health inequalities: developing new directions. Health and Social Care in the Community, 15, 306-312. doi: 10.1111/j.1365-2524.2007.00688.x

Brett, J., Staniszewska, S., Mockford, C., Herron-Marx, S., Hughes, J., Tysall, C., \& Suleman, R. (2014). Mapping the impact of patient and public involvement on health and social care research: a systematic review. Health Expectations, 17, 637-650. doi: $10.1111 / \mathrm{j} .1369-7625.2012 .00795 . x$

Chambers, M., \& Hickey, G. (2012). Service user involvement in the design and delivery of education and training programmes leading to registration with the Health Professions Council. doi: 79.170.44.111

Cleminson, S., \& Moesby, A. (2013). Service user involvement in OT education: an evolving involvement. Journal of Mental Health Training, Education and Practice, 8, 5-14. Retrieved from: http://dx.doi.org/10.1108/17556221311307989

Department of Health (2002). Requirements for social work training. London: HMSO.

Department of Health (2006). Our health, our care, our say: a new direction for community services. CM6737. London: Department of Health.

Faulkner, A. (2010). Changing our worlds: examples of user controlled research in action. Eastleigh: INVOLVE.

Francis, R. (2013). Report of the Mid Staffordshire NHS Foundation Trust Public Inquiry. London: The Stationery Office.

Gillard, S., \& Stacey, E. (2005). All talk: experiencing user-led research. A Life in the Day, 9(2), 27-30. Retrieved from: http://dx.doi.org/10.1108/13666282200500017

Gillard, S., Simons, L., Turner, K., Lucock, M., \& Edwards, C. (2012). Patient and public involvement in the coproduction of knowledge: reflection on the analysis of qualitative data in a mental health study. Qualitative Health Research, 22, 1126-1137. doi: $10.1177 / 1049732312448541$

Glasby, J., \& Beresford, P. (2006). Who knows best? Evidence-based practice and the service user contribution. Critical Social Policy, 26, 268-284.

doi: $\underline{10.1177 / 0261018306059775}$ 
Harris, J. (2003). The Social Work Business. London: Routledge.

Hutchinson, A., \& Lovell, A. (2013). Participatory action research: moving beyond the mental health 'service user' identity. Journal of Psychiatric and Mental Health Nursing, 20, 641-649. doi: 10.1111/jpm.12001

Jary, D. (2014). The marketisation of UK higher education. Journal of Widening Participation and Lifelong Learning, 16(3), 71-77. doi: http://dx.doi.org/10.5456/WPLL.16.3.71

Lathlean, J., Burgess, A., Coldham, T., Gibson, C., Herbert, L., Levett-Jones, T., ... Tee, S. (2006). Experiences of service user and carer participation in health care education. Nurse Education Today, 26, 732-737. doi: 10.1016/j.nedt.2006.07.017

McCutcheon, K., \& Gormley, K. (2014). Service-user involvement in nurse education: partnership or tokenism?. British Journal of Nursing, 23, 1196-1199. doi: http://dx.doi.org/10.12968/bjon.2014.23.22.1196

McKeown, M., Malihi-Shoja, L., Hogarth, R., Jones, F., Holt, K., Sullivan, ... CIT. (2012). The value of involvement from the perspective of service users and carers engaged in practitioner education: Not just a cash nexus. Nurse Education Today, 32, 178-184. doi: 10.1016/j.nedt.2014.03.016

McKeown, M., Dix, J., Jones, F., Carter, B., Malihi-Shoja, L., Mallen, E., \& Harrison, N. (2014). Service user involvement in practitioner education: Movement politics and transformative change. Nurse Education Today, 34, 1175-1178. doi: http://dx.doi.org/10.1016/j.nedt.2014.03.016

Patterson, S., Trite, J., \& Weaver, T. (2014). Activity and view of service users involved in mental health research: UK survey. British Journal of Psychology, 205, 68-75. doi:_ 10.1192/bjp.bp.113.128637

Rhodes, C., (2012). User involvement in health and social care education: A concept analysis. Nurse Education Today, 32, 185-189. doi: 10.1016/j.nedt.2011.11.012

Rhodes, C., Hardy, J., Padgett, K., Symons, J., Tate, J., \& Thornton, S. (2014). The Health and Well-being of Service User and Carer Educators: a Narrative Enquiry into the Impact of Involvement in Healthcare Education. International Journal of Practicebased Learning in Health and Social Care, 2, 51-68. doi:10.11120/pblh.2013.00025

Speed, S., Griffiths, J., Horne, M., \& Keeley, P. (2012). Pitfalls, perils and payments: Service user, carers and teaching staff perceptions of the barriers to involvement in nursing education. Nurse Education Today, 32, 829-834. doi: 10.1016/j.nedt.2012.04.013

Towle A., Bainbridge, L., Godolphin, W., Katz, A., Kline, C., Lown, B., Thistlewaite, J. (2010). Active patient involvement in the education of health professionals. Medical Education, 44, 64-74. doi:10.1111/j.1365-2923.2009.03530.x

Towle, A., \& Godolphin, W. (2015). Patients as teachers: promoting their authentic and autonomous voices. The Clinical Teacher, 12, 149-154. doi: 10.1111/tct.12400 
The National Health Service and Community Care Act (1990). Retrieved from: http://www.legislation.gov.uk/ukpga/1990/19/section/46

Wallcraft, J., Fleischmann, P., \& Schofield, P. (2012). The involvement of users and carers in social work education: A practice benchmarking study. London: Social Care Institute for Excellence. Retrieved from:

http://www.scie.org.uk/publications/reports/report54.pdf 